\title{
ECONOMIA SOLIDÁRIA E ESTRATÉGIA: ENTRE PRINCÍPIOS E PRAGMATISMO
}

\author{
SOLIDARITY ECONOMY AND STRATEGY: PRINCIPLES AND BETWEEN \\ PRAGMATISM
}

\section{ECONOMÍA SOLIDARIA Y ESTRATEGIA: PRINCIPIOS Y ENTRE PRAGMATISMO}

\section{Luís Miguel Luzio dos Santos}

Doutor em Ciências Sociais pela Pontifícia Universidade Católica de São Paulo - PUC/SP

Professor da Universidade Estadual de Londrina - UEL

E-mail: lmig@uol.com.br (Brasil)

\section{Saulo Fabiano Amâncio Vieira}

Doutor em Administração pela Universidade Nove de Julho - UNINOVE

Professor da Universidade Estadual de Londrina - UEL

E-mail: saulo@uel.br (Brasil)

\section{Benilson Borinelli}

Doutor em Ciências Sociais pela Universidade Estadual de Campinas - UNICAMP

Professor da Universidade Estadual de Londrina - UEL

E-mail: benilson@uel.br (Brasil) 
Economia Solidária e Estratégia: Entre Princípios e Pragmatismo

\section{ECONOMIA SOLIDÁRIA E ESTRATÉGIA: ENTRE PRINCÍPIOS E PRAGMATISMO}

\section{RESUMO}

As contradições do mundo contemporâneo atingem níveis alarmantes o que coloca em risco a sustentabilidade planetária, tanto em termos ambientais e sociais como econômicos, o que obriga a repensar o atual modelo econômico-produtivo. A Economia Solidária (ES) apresenta-se como uma alternativa ao sistema vigente, com centralidade na inclusão socioeconômica, na autogestão, na equidade e na solidariedade. $\mathrm{O}$ estudo aqui apresentado procurou identificar e analisar as estratégias utilizadas por três empreendimentos de economia solidária que conseguiram atingir um certo grau de consolidação e êxito diante dos demais empreendimentos congêneres em atuação na região de Londrina-PR. O artigo buscou, por meio de pesquisa exploratória, descritiva e qualitativa, via análise documental e entrevistas semiestruturadas junto aos principais dirigentes de cada um dos empreendimentos, entender a escolha das estratégias e sua atuação no mercado. Percebe-se que os modelos estratégicos convencionais não se aplicam à maioria dos empreendimentos solidários, considerando suas particularidades e propósitos. A questão e o ponto de tensão que emergem dessas experiências são como substituir ou combinar a lógica tradicional de maximização de lucro com a maximização da inclusão social e a sociabilidade alternativa, elementos fundamentais da Economia Solidária.

Palavras-chave: Economia Solidária; Estratégia; Sustentabilidade.

\section{SOLIDARITY ECONOMY AND STRATEGY: PRINCIPLES AND BETWEEN PRAGMATISM}

\section{ABSTRACT}

The contradictions of the contemporary world reach alarming levels, which endangers the planetary sustainability, both environmental, social, or economic, which requires rethinking the current economic - production model. The Solidarity Economy (SE ) is presented as an alternative to the current system, focused on the socio-economic inclusion, self-management, equity and solidarity. The present study sought to identify and analyze the strategies used by three developments of solidarity economy that have achieved a certain degree of consolidation and success on projects from all congeners in action in the region of Londrina - PR. The article sought through exploratory, descriptive and qualitative research via document analysis and interviews with leading executives from each of the projects, understand the choice of strategies and their performance in the market. It is perceived that conventional strategic models do not apply to most solidary enterprises considering its particularities and purposes. The question and the point of tension that emerge from these experiments is how to replace or combine the traditional logic of profit maximization with maximization of social inclusion and alternative sociability, fundamental elements of the Solidarity Economy.

Keywords: Solidarity Economy; Strategy; Sustainability. 
ECONOMÍA SOLIDARIA Y ESTRATEGIA: PRINCIPIOS Y ENTRE PRAGMATISMO

\section{RESUMEN}

Las contradicciones del mundo contemporáneo alcanzan niveles alarmantes, lo que pone en peligro la sostenibilidad del planeta, tanto ambientales, sociales o económicos, que requiere repensar el modelo de producción económica actual. La Economía Solidaria ( SE) se presenta como una alternativa al sistema actual, centrado en la inclusión socio- económica, la autogestión, la equidad y la solidaridad. El presente estudio trata de identificar y analizar las estrategias utilizadas por tres desarrollos de la economía solidaria que han alcanzado un cierto grado de consolidación y el éxito en los proyectos de todos los congéneres en acción en la región de Londrina -PR. El artículo busca a través de la investigación exploratoria, descriptiva y cualitativa a través de análisis de documentos y entrevistas semiestrututuradas con los principales líderes de cada uno de los proyectos, entender la elección de las estrategias y su desempeño en el mercado. Se percibe que los modelos estratégicos convencionales no se aplican a la mayoría de los emprendimientos solidarios, considerando sus particularidades y finalidades. La pregunta y el punto de tensión que surge de estos experimentos es la forma de sustituir o combinar la lógica tradicional de la maximización del beneficio con la maximización de la inclusión social y la sociabilidad alternativa, los elementos fundamentales de la Economía Solidaria.

Palabras-clave: Economía Solidaria; Estrategia; Sostenibilidad. 


\section{INTRODUÇÃO}

O Brasil construiu sua história dentro de uma racionalidade em que as elites econômicas apoderaram-se do Estado como extensão dos seus próprios domínios individuais, confundindo a esfera pública com a privada, numa relação promíscua que se foi naturalizando ao longo do tempo. A aliança entre poder econômico e político gerou uma das mais injustas sociedades do mundo, em que nem mesmo a abundância de recursos naturais foi suficiente para assegurar o mínimo de bemestar para a maioria da população. As imensas potencialidades nacionais ficaram sob domínio de um reduzidíssimo número de famílias, condenando os demais a condição de subserviência crônica e de exploração contínua, o que criou um quadro de pobreza crônica, exclusão endêmica e entendida como natural (FURTADO, 2009).

Diante das contradições que marcam nossa realidade como nação, emergem alternativas no campo econômico e social que ousam ao se propor a trabalhar dentro de uma lógica diferente, subordinando a dimensão econômica à inclusão social e ao equilíbrio ambiental. De acordo com Singer (2002), a Economia Solidária (ES) apresenta-se como um conjunto de atividades econômicas de produção, distribuição, consumo, poupança e crédito, organizadas coletivamente de acordo com os princípios da autogestão. Esta forma de produção visa transformar o trabalho num meio de libertação humana dentro do processo de democratização econômica, alternativa à dimensão alienante do modelo de trabalho assalariado capitalista.

O universo compreendido pelos empreendimentos de Economia Solidária no Brasil, ainda que tenha crescido na última década, apresenta baixa representatividade na economia nacional, o que expressa a enorme dificuldade destes empreendimentos em se consolidar no mercado. Grande parte das limitações inerentes a estas organizações decorre da escassez de recursos materiais, financeiros, informacionais e administrativos, o que os coloca numa posição desfavorável e muitas vezes inviável diante do mercado competitivo. Como alerta Barbosa (2007), não se pode querer resolver problemas que têm origem histórica e estrutural, simplesmente transferindo a responsabilidade para o plano individual, principalmente quando se trata das populações mais fragilizadas pelas iniquidades nacionais.

Diante de um panorama nebuloso e repleto de contradições, multiplicam-se as análises e interpretações, o que dá ao fenômeno um caráter eminentemente multidisciplinar. A gestão ainda é um campo bastante incipiente dentro da economia solidária, os esforços em desenvolver mecanismos administrativos específicos para estas organizações continuam carenciados, o que reduz o potencial de desenvolvimento dessas iniciativas. Ao ter contato mais direto com esses empreendimentos, é fácil perceber a falta de ferramentas administrativas apropriadas, reduzindo-se 
as ações a "apagar incêndios" e poucas vezes se avança para a dimensão estratégica, com propósitos bem definidos e sintonizados com a realidade do mercado, de forma a lhes garantir sustentabilidade ao longo do tempo.

Quanto à organização metodológica do trabalho, trata-se de um estudo qualitativo através da análise de casos múltiplos, compreendendo três iniciativas de Economia Solidária em atuação na cidade de Londrina/PR, selecionadas por conveniência, considerando a sua consolidação no mercado e relevância socioeconômica. Sendo assim, o objetivo central do presente estudo é identificar as estratégias utilizadas por esses empreendimentos solidários que, mesmo utilizando posições estratégicas distintas, destacam-se pelos resultados e vigor diante dos demais empreendimentos congêneres em atuação na região. Foram realizadas entrevistas entre janeiro a março de 2013 junto aos principais dirigentes de cada uma das organizações, além de consulta a documentos como estatutos e atas, de forma a reunir elementos capazes de auxiliar na caracterização dos empreendimentos e, principalmente, identificar a estratégia que mais contribuiu para sua robustez econômica e social.

\section{REFERENCIAL TEÓRICO}

Nesta seção abordaram-se os seguintes temas: problemática social e economia solidária bem como a importância da gestão estratégica em empreendimentos solidários.

\subsection{PROBLEMÁTICA SOCIAL E ECONOMIA SOLIDÁRIA}

O problema do agravamento das desigualdades sociais em todo o mundo, a crise ambiental e o enfraquecimento da solidariedade são algumas das características mais marcantes do nosso momento histórico. Isso se deve a vários fatores, entre eles a priorização do modelo econômico neoliberal, que reduziu a intervenção do Estado na economia, desonerou capitais especulativos, concentrou renda e poder nas mãos de um pequeno grupo de corporações transnacionais, o que se tornou uma verdadeira ameaça à democracia, condenando milhões de pessoas ao total ostracismo. Como resultado do domínio, quase absoluto, das leis de livre mercado em todo o mundo e o enfraquecimento do Estado na configuração e regulação dessas forças, emerge a necessidade dos grupos excluídos encontrarem mecanismos alternativos de sobrevivência (SANTOS, 2002)

Além da polarização econômica, a própria vida na terra encontra-se ameaçada em virtude do 
modelo de produção extrativista, alimentado por um consumo compulsivo e ilimitado, num planeta de recursos limitados, algo inconciliável e insustentável. O modelo de desenvolvimento atual demonstra-se inviável e incapaz de apresentar soluções à altura dos problemas que ele mesmo ajudou a criar. São necessários novos modelos de produção, consumo e sociabilidade capazes de garantir o bem-viver humano e a preservação da vida na terra em toda a sua diversidade (CATTANI 2003).

Diante dos dilemas e contradições do nosso período histórico, vêm surgindo novos experimentos organizacionais, que bebem do cooperativismo primitivo iniciado no séc. XIX pelos chamados socialistas utópicos e que hoje renasce sob o "guarda chuva" conceitual de Economia Solidária. Conforme explicita Singer (2002), Economia Solidária é um sistema socioeconômico aberto, amparado nos valores da cooperação e da solidariedade no intuito de atender às necessidades e desejos materiais e de convivência, mediante mecanismos de democracia participativa e de autogestão, visando a emancipação e o bem-estar individual, comunitário, social e ambiental.

A Economia Solidária no Brasil surge impulsionada por um acelerado processo de desemprego que atingiu a nação nos anos de 1980 e 1990, o que fez com que vários movimentos sociais apoiassem alternativas de geração de trabalho e renda para as classes populares mais afetadas. Aliado a esses movimentos, o setor acadêmico passou a se envolver mais ativamente com a causa, criando incubadoras e centros de apoio a esses empreendimentos, o que acabaria por se consolidar após a criação da SENAES - Secretaria Nacional de Economia Solidária em 2003, ligada ao Ministério do Trabalho do Governo Federal (POCHMANN, 2004).

A Economia Solidária na cidade de Londrina-PR, ainda que tenha algumas experiências na década de 1990, apresenta os primeiros empreendimentos formais a partir de 2003, o que se deve à criação da SENAES - Secretaria Nacional de Economia Solidária, por iniciativa do Governo Federal, que deu visibilidade ao tema e impulsionou o desenvolvimento dessa modalidade de empreendimentos. No caso específico de Londrina, um alinhamento partidário entre o Governo Federal e o Municipal, facilitou a criação em 2005 do CPES - Centro Público de Economia Solidária, que foi responsável por fomentar e dar apoio a empreendimentos dessa natureza na cidade e região. Na mesma época, surgiu a INTES - Incubadora de Empreendimentos de Economia solidária da Universidade Estadual de Londrina, que a exemplo de outras incubadoras universitárias já em atuação por todo o país, passou a fomentar e a apoiar grupos de Economia Solidária nos mais variados segmentos. Além destas duas forças institucionais, foi emblemático o esforço dos catadores de materiais recicláveis de Londrina, que durante toda a década de 2000 e um doloroso processo de luta, conseguiram se organizar em forma de cooperativa e tornaram-se parceiros do 
poder público na coleta seletiva da cidade o que lhes garantiu avanços socioeconômicos consideráveis. A primeira cooperativa de coleta seletiva, COOPERSIL - Cooperativa de Catadores de Materiais Recicláveis de Londrina surgiu em 2010 e desde o início aderiu aos princípios da Economia Solidária e tornar-se-ia referência no setor. (CRUZ; LUZIO-DOS-SANTOS 2010)

\subsection{ESTRATÉGIA E ECONOMIA SOLIDÁRIA}

Pode-se entender por Estratégia como uma técnica administrativa que procura ordenar ideias com a finalidade de definir uma referência a ser perseguida, levando em conta os ambientes que rodeiam a organização e que a influenciam direta ou indiretamente. Apoiando-se num vasto repertório de informações e levando em conta os recursos disponíveis, garantem-se condições para que a organização possa definir as estratégias que melhor poderão atingir os objetivos propostos. Em síntese, a definição de Estratégia compreende um processo que se inicia pela análise sistemática das ameaças e oportunidades apresentadas pelo ambiente externo à organização e os pontos fortes (competências da organização) e fracos (debilidades da organização), que possibilitarão definir os objetivos capazes de projetar a empresa para o futuro e que se viabilizam por meio do estabelecimento das estratégias de ação mais adequadas (OLIVEIRA, 2005).

Vieira et al (2013) ao descreverem o trabalho de Bailey e Avery (1998) destacam que o processo de desenvolvimento da estratégia não pode ser sempre caracterizado como intencional e planejado. Em concordância com Whittington (2003) e Mintzberg, Ahlstrand e Lampel (2005), esses autores afirmam que a estratégia pode surgir sob o efeito de diferentes influências, sendo seis as perspectivas: Planejamento; Incremental; Cultural; Política; Comando; Escolha Forçada (BAILEY e AVERY (1998, p. 182).

De acordo com Mintzberg; Ahlstrand; Lampel (2005), uma estratégia bem formulada permite ordenar e alocar recursos organizacionais com vistas a garantir uma posição superior no mercado, considerando suas competências e vantagens competitivas e ao mesmo tempo, tendo consciência de suas debilidades diante de um ambiente em constante mutação, antecipando ações, tanto de proteção como aproveitando os sinais para se projetar para o futuro.

Já Miles e Snow (1978) propõem em seus estudos o que chamaram de ciclo adaptativo, definido como o modelo geral da fisiologia do comportamento organizacional. Segundo os autores, este ciclo é composto de três conjuntos de problemas que a organização deve solucionar de maneira consistente. São eles: definir um domínio de produto/mercado; seguido pelo problema de engenharia, que sugere uma solução tecnológica; finalizando com o terceiro problema 
administrativo, que abrange os processos administrativos, bem como a estrutura organizacional. A partir da interação da organização com as dimensões do ciclo adaptativo, induz-se ao tipo de estratégia adotada pela organização, sendo que os autores descrevem como podendo ser: (a) Defensiva; (b) Prospectora; (c) Analítica; (d) Reativa. VIEIRA et al (2013)

A Estratégia, pelo seu grau de importância, tende a tornar-se mais participativa, envolvendo diferentes níveis e funções dentro da empresa. Deve-se considerar que todos os membros da organização têm informações e pontos de vista privilegiados, os quais devem ser incluídos no planejamento de forma abrangente, capaz de integrar a todos num projeto comum, gerando maior comprometimento, motivação, além de facilitar e potencializar o atingimento dos objetivos organizacionais. Como expõe Oliveira (2005, p. 25) "[...] grande número de empresas não tem ou não sabe quais são suas estratégias". Essa realidade é particularmente comum e dramática nos empreendimentos de ES que, por falta de planejamento e de estratégia, limitam-se a reagir diante das contingências impostas pelos diferentes ambientes organizacionais, o que tende a fragilizá-las ainda mais, considerando a sua habitual situação de escassez de recursos, tanto técnicos, informacionais quanto materiais.

A organização necessita de um monitoramento sistemático e contínuo dos ambientes à sua volta para que se possa adequar a esse contexto, considerando a turbulência e imprevisibilidade cada vez mais comuns, que impõem um plano de alinhamento entre a realidade do mercado e as potencialidades da organização, considerando elementos diversos e complexos que interagem e que devem ser acompanhados permanentemente, pois podem se tornar ameaças, mas também oportunidades importantes. São eles: economia, cultura, demografia, política, além da concorrência, fornecedores e necessidades e desejos dos consumidores (Oliveira 2005).

A realidade que povoa os empreendimentos de Economia Solidária apresenta muitas singularidades e assim rejeita meras repetições ou adaptações simplórias de modelos estratégicos convencionais. Todavia, não se deve cair no extremo oposto e em nome de um discurso ideologizado, se desprezar os instrumentos e o amplo conhecimento adquirido pelas ciências no campo da gestão. A aproximação da gestão em relação ao universo da Economia Solidária é um desafio imprescindível para o seu fortalecimento, não só em relação às questões técnicas, que terão de alinhar-se a essa realidade específica, considerando valores e cultura própria, mas também a abertura e aderência a certas imposições de uma economia de mercado, sem ser cooptada pela lógica corporativa hegemônica. Cercar-se de amplo instrumental de gestão e conseguir filtrá-lo e adequá-lo ao universo solidário é um dos grandes desafios da Economia Solidária, pois esta não poderá se esquecer de que os seus produtos e serviços ingressam no mesmo mercado das empresas capitalistas, o que as obriga a alcançar níveis de efetividade similares . 
Luzio-dos-Santos (2010, p. 9) realizou um esforço para entender e sistematizar as principais estratégias utilizadas pelos empreendimentos de Economia Solidária e que lhes proporcionavam maior vigor e sustentabilidade. $\mathrm{O}$ autor levantou 04 estratégias básicas que tendem a representar a grande maioria das organizações que se apresentam mais consolidadas no mercado, como se descreve no quadro abaixo.

\begin{tabular}{|c|c|}
\hline \multicolumn{2}{|r|}{ ESTRATÉGIAS PARA ECONOMIA SOLIDÁRIA } \\
\hline $\begin{array}{l}\text { Estratégia de } \\
\text { Integração e } \\
\text { Convergência }\end{array}$ & $\begin{array}{l}\text { A estratégia de integração ou convergência apoia-se na união de empreendimentos } \\
\text { individuais ou pequenas iniciativas dentro do mesmo segmento de atividade, } \\
\text { potencializando-se a capacidade de produção e desenvolvimento, proporcionando } \\
\text { sinergia entre os empreendimentos de forma melhor enfrentar a concorrência do mercado } \\
\text { tradicional. Salienta-se a importância de se criarem ações integradas, que tanto se } \\
\text { complementam, quando uma organização solidária fornece outra, como se } \\
\text { potencializam, ao produzirem ou comercializarem em conjunto, aumentando o poder de } \\
\text { barganha, o acesso à tecnologia, o desenvolvimento conjunto de novos produtos, a } \\
\text { distribuição e a divulgação. }\end{array}$ \\
\hline $\begin{array}{l}\text { Estratégia de } \\
\text { Escopo }\end{array}$ & $\begin{array}{l}\text { A estratégia de escopo é especialmente indicada para empreendimentos de pequeno porte, } \\
\text { que dificilmente conseguiriam se manter através de ganhos de escala sustentáveis. É } \\
\text { apropriada a atuação em segmentos específicos que se viabilizam através da capacidade } \\
\text { de diferenciação e muitas vezes de ofertas customizadas. Alguns empreendimentos de } \\
\text { Economia Solidária atuam em segmentos de demanda fixa e programada, num processo } \\
\text { contratual (ainda que informal), procurando-se alinhar as necessidades de um grupo de } \\
\text { consumidores com a capacidade de oferta dos empreendimentos solidários, garantindo-se } \\
\text { o fornecimento permanente de produtos e serviços de giro rápido, como artigos de } \\
\text { higiene e limpeza, verdura, produtos orgânicos, pães, entre outros. Esta estratégia poderá } \\
\text { ser potencializada com entrega a domicílio e a adesão inicial de consumidores adeptos do } \\
\text { consumo solidário. }\end{array}$ \\
\hline $\begin{array}{c}\text { Estratégia de } \\
\text { Empoderamento } \\
\text { Comunitário }\end{array}$ & $\begin{array}{l}\text { Essa estratégia também tem apresentado bons resultados ao buscar suprir uma } \\
\text { necessidade comunitária, garantindo a permanência dos recursos na região, contribuindo } \\
\text { com o fortalecimento da economia local. Para potencializar essa estratégia é comum o } \\
\text { uso de uma moeda comunitária própria, de forma a fomentar e estimular o comércio } \\
\text { dentro da comunidade, evitando a saída de recursos. Exemplos podem ser encontrados } \\
\text { em serviços de construção civil, confecção, sapataria, padaria e mercado. }\end{array}$ \\
\hline $\begin{array}{c}\text { Estratégia de } \\
\text { Fornecimento } \\
\text { Público } \\
\text { Privilegiado }\end{array}$ & $\begin{array}{l}\text { Esta estratégia apoia-se na defesa de políticas públicas de incentivo à comercialização } \\
\text { dos produtos e serviços da Economia Solidária, estabelecendo-se cotas ou mecanismos de } \\
\text { descriminação positiva a fim de privilegiar o fornecimento de produtos/serviços de } \\
\text { empreendimentos de Economia Solidária. Essa estratégia parece ser uma das mais } \\
\text { promissoras ao garantir um mercado fixo estável. } \\
\text { Como exemplo, destacam-se os empreendimentos de reciclagem, que alinham trabalho e } \\
\text { renda com prestação de um serviço essencial à sociedade e a lei da merenda escolar que } \\
\text { obriga que } 30 \% \text { dos alimentos sejam adquiridos de empreendimentos de agricultura } \\
\text { familiar. }\end{array}$ \\
\hline
\end{tabular}

Quadro 1 - Modelo estratégico para empreendimento de Economia Solidária Fonte: Luzio-dos-Santos (2010, p. 11) 
Embora o constructo proposto pelo autor seja preliminar e esteja aberto a novas contribuições, é um primeiro esforço para compreender a forma de atuação dos empreendimentos de Economia Solidária, dadas as suas particularidades e ao mesmo tempo a sua necessidade de se firmar em mercados exigentes e competitivos, garantindo trabalho e renda para seus membros, dentro de um novo modelo de sociabilidade que, para se firmar, precisará demonstrar as suas potencialidades, não só de inclusão social, mas também de sustentabilidade econômica.

Paul Singer (2002) é categórico ao afirmar que a Economia Solidária só se tornará uma proposta crível caso consiga demonstrar a sua efetividade no seio do mercado convencional. Ainda que algum tipo de vantagem ou proteção institucional seja justificável e de início necessária, estes empreendimentos deverão ultrapassar essa fase e serem capazes de se manter pela qualidade e eficiência de seus serviços. Todavia, o conceito de eficiência não deve se limitar à simples condição econômica - ou a ES não se tornará a alternativa que almeja ser - precisa avançar para outros tipos de eficiência, como a social e a ecoeficiência, garantindo inclusão social e preservação ambiental. Só assim estas iniciativas preservarão sua identidade progressista e poderão posicionar-se como alternativas legítimas e superiores ao modelo capitalista de empresa (SACHS, 2006).

Diante de um ambiente inóspito onde a competição se dá de forma assimétrica, com regras viciadas, com vantagens acumuladas por grupos historicamente privilegiados, parece haver um consenso em se acreditar que os empreendimentos de Economia Solidária só terão futuro, caso sejam articulados em forma de rede, formando cadeias produtivas integradas, em que se potencializam as iniciativas individuais, aproveitando a vocação cooperativa dos empreendimentos. Além da desejável articulação entre os empreendimentos de ES, a proximidade em relação a instituições de apoio, como poder público, movimentos sociais, ONGs, sindicatos e universidades, são indispensáveis, além de um movimento paralelo capaz de sensibilizar os consumidores a aderirem ao consumo responsável e solidário (LUZIO dos SANTOS, 2010).

\section{PROCEDIMENTOS METODOLOGICOS}

O estudo aqui apresentado pode ser classificado como exploratório, descritivo e de natureza qualitativa, através da análise de casos múltiplos, compreendendo três iniciativas de Economia Solidária em atuação na cidade de Londrina/PR e que apresentam posicionamentos estratégicos distintos, conforme o Modelo Estratégico para Empreendimento de Economia Solidária apresentado no referencial teórico.

Em relação à seleção das unidades de análise, foi usado como critério de seleção a 
autonomia financeira; renda per capita, tempo de atuação e a distinção entre as estratégias utilizadas. Foram selecionados os empreendimentos: Padaria Comunitária PAMA; Grupo de Agroecologia Verdes Campos e a Cooperativa de Reciclagem de Resíduos Sólidos de Londrina Cooperregião.

Quanto aos procedimentos de coleta de dados, as informações necessárias à compreensão do fenômeno estudado, foram coletadas via entrevistas semi-estruturadas entre janeiro e março de 2013. Foi entrevistado um membro de cada empreendimento, considerando-se o tempo de trabalho na entidade ou a posição de liderança ocupada no período.

A análise dos dados, de caráter qualitativo, foi iniciada após as transcrições das entrevistas, sendo que foram selecionados elementos das mesmas para que se pudesse realizar a triangulação dos dados coletados, considerando também a análise de documentos e o método de observação.

\section{APRESENTAÇÃO DOS RESULTADOS}

O planejamento diante do anteposto serve como ponte, além de ferramenta primordial para que sejam alcançadas as metas previamente definidas e assim projetar-se consistentemente para o futuro, com clareza de seu papel e poder de ação. Com isto, observa-se que, dentro dos grupos entrevistados, a falta de planejamento e de clareza na definição de prioridades e potencialidades são uma constante que ameaça seriamente o seu desempenho. Verifica-se que não há preocupação em definir um foco para seus produtos e serviços, considerando o perfil de seus consumidores. $\mathrm{O}$ quadro, a seguir, descreve as estratégias de mercado que se enquadram nas atuais práticas dos grupos entrevistados, assim como a justificativa para tal classificação. 
ESTRATÉGIAS UTILIZADAS PELOS EMPREENDIMENTOS SOLIDÁRIOS PESQUISADOS

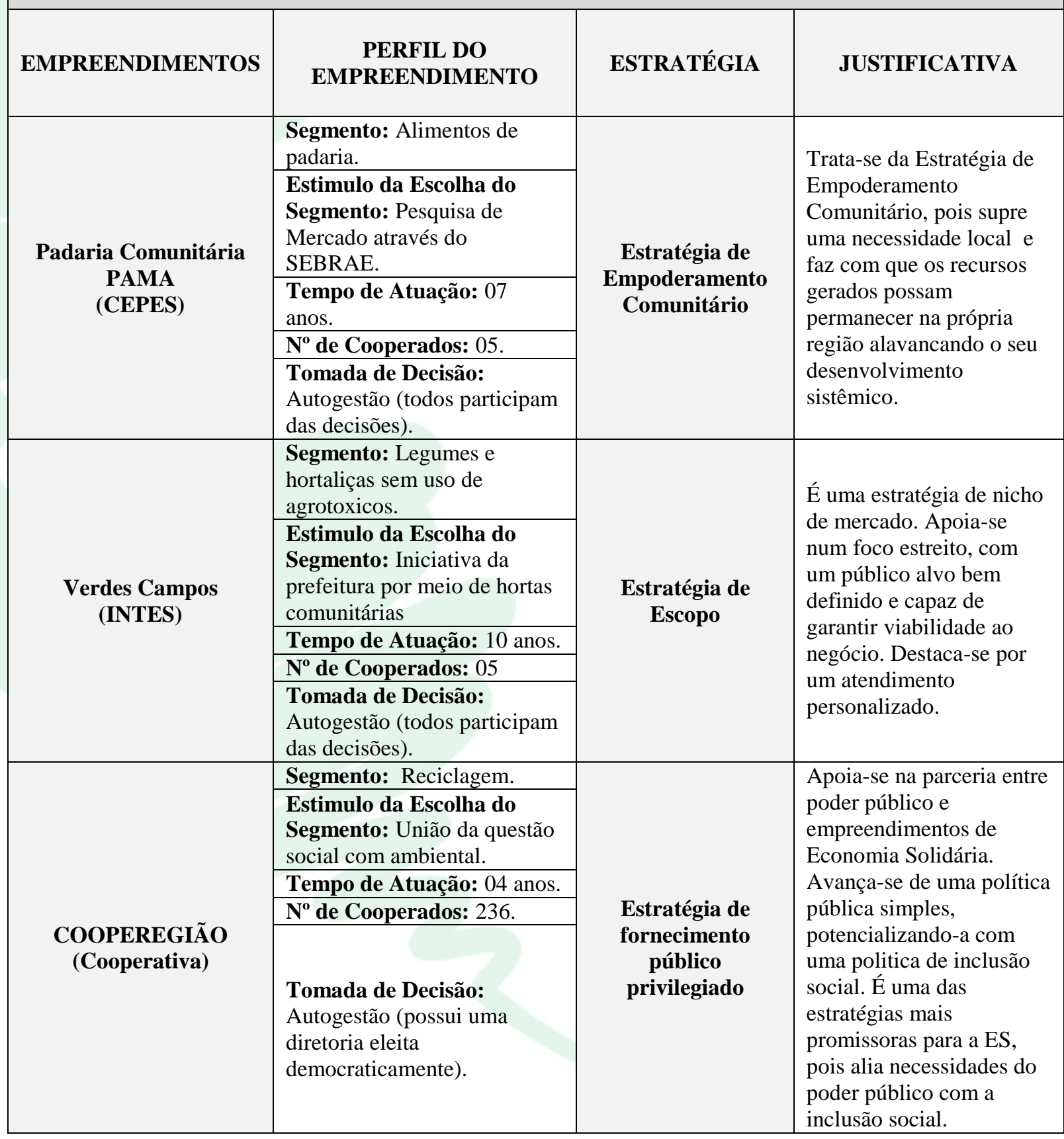

Quadro 2 - Estratégias desenvolvidas pelos empreendimentos entrevistados Fonte: Elaborado pelos autores.

A padaria Comunitária PAMA localiza-se num distrito pertencente à cidade de Londrina que possui cerca de 3000 habitantes. Iniciaram-se as atividades da padaria em 2006 como um grupo incubado dentro do CPES - Centro Público de Economia Solidária, um tipo de incubadora municipal de empreendimentos de economia solidária. Entre mais de 80 grupos de produção que já 
passaram pelo CPES, apenas a Padaria Comunitária PAMA conseguiu autonomia financeira e caminhar sozinha. Às principais razões da sua consolidação, destaca-se a sua atuação privilegiada na região, já que foi a primeira padraria da região, assegurando a adesão de praticamente toda a população, podendo-se definir como um modelo de Estratégia de Empoderamento Comunitário, ao conseguir viabilizar-se por meio do atendimento a uma necessidade real da população. A Padaria Comunitária PAMA destaca-se por ter partido de um estudo preliminar que apontou a atividade como uma carência latente na região. Tal prerrogativa encontra eco em Luzio-dos-Santos (2010, p. 17) quando este salienta que "o principal problema inerente ao processo de formação de estratégia dos empreendimentos de ES é o recorrente enfoque dado ao produto e não ao mercado".

O grupo Verdes Campos foi inicialmente incubado pela INTES - Incubadora Tecnológica de Empreendimentos de Economia Solidária da Universidade Estadual de Londrina, mas acabou por alcançar autonomia financeira e consistência técnica o que lhe garantiu emancipação em relação à incubadora. O empreendimento Verdes Campos trabalha no segmento de verduras e hortaliças sem uso de agrotóxicos, comercializando seus produtos a domicilio, conseguindo a adesão de um público fiel e uma demanda constante. O empreendimento Verdes Campos pode ser caracterizado dentro da estratégia de escopo, a qual é adequada ao tipo de produto e mercado em que atua alimentos orgânicos - segmento em franca expansão e que se distingue do varejo massificado de alimentos. Atendem um público especifico, adequando-se às suas necessidades particulares, garantindo demanda fixa e programada, apresentando um vínculo quase contratual com os consumidores.

O empreendimento Verdes Campos, pela sua característica particular pode beneficiar-se com a lei $n^{\text {o }} 11.947 / 2009$ que define que, no mínimo 30\% dos recursos repassados pelo Fundo Nacional de Desenvolvimento da Educação - FNDE para a aquisição de alimentos para a merenda escolar, advenham da agricultura familiar, priorizando-se os assentamentos de reforma agrária, as comunidades tradicionais indígenas e quilombolas (de acordo com o Artigo 14).

A Cooperativa de Reciclagem de Resíduos Sólidos - COOPEREGIÃO utiliza a Estratégia de fornecimento público privilegiado, ou seja, atendem a uma demanda do Poder Público Municipal por meio de contrato formal, o que lhe assegura o privilégio na prestação de um serviço que é da responsabilidade da prefeitura. Este empreendimento vem proporcionando resultados bastante expressivos, levando em conta o número de participantes e os avanços socioeconômicos já alcançados. De acordo com Luzio-dos-Santos (2010, p. 33) a "estratégia de fornecimento público privilegiado" ou também conhecida por demanda institucional, é uma das mais promissoras para os empreendimentos de ES pois, ao criarem-se mecanismos como cotas ou mesmo algum tipo de 
reserva de mercado, asseguram-se certas vantagens para empreendimentos solidários, aliando-se a prestação de um serviço público fundamental à inclusão de populações antes em condição de vulnerabilidade social extrema.

Hoje a COOPERSIL conta com um número de cooperados expressivo, atinge próximo a 250 membros, o que lhe dá maior visibilidade e poder de negociação, conseguindo dobrar o ganho médio mensal por cooperado nos últimos 24 meses, além de ser visível a melhora nas condições de vida de seus integrantes. Todos descontam para a previdência social, muitos já conquistaram casa própria e outros estão próximos de conseguí-la, além de avanços não materiais, tão ou mais importantes, como melhoria da autoestima, desenvolvimento comunitário e maior participação cívica. Como principais desafios destacam a melhoria das condições de vida, a inclusão de um maior número de membros, além de conseguirem agregar maior valor aos serviços prestados.

Uma questão que merece ser salientada é a baixa ou quase inexistente articulação estratégica entre os empreendimentos de Economia Solidária. A Estratégia de Integração e Convergência apresentada no modelo de Luzio-dos-Santos (2010) e entendida como essencial para a potencialização dos empreendimentos diante de um ambiente que lhes é, à partida, desfavorável. A importância da articulação em rede é praticamente um consenso entre os teóricos ligados à Economia Solidária, tais como Singer(2002), Mance (2000), Cattani (2007) entre outros...Só a articulação em redes será capaz de potencializar e complementar as ações individuais e garantir-lhes o vigor necessário ao enfretamento de um ambiente geralmente inóspito. Além do mais, só a articulação entre as diferentes iniciativas poderá ambicionar tornar-se uma alternativa de fato ao modelo capitalista de empresa, ou não passarão de experimentos isolados, pitorescos, mas de irrelevância sistêmica.

\section{CONSIDERAÇÕES FINAIS}

É fácil perceber que o sistema econômico hegemônico não tem como prioridade a inclusão de todo o contingente de trabalhadores, mesmo quando a economia passa por um processo de expansão, a incorporação de todo o contingente de trabalhadores disponíveis num país ou região, não é prioridade e até uma margem de desempregados é vista como desejável pois servem como “peças de reposição". A empresa capitalista é alicerçada na busca pela maximização infinita do lucro e a acumulação privada do excedente, o que naturalmente cria uma situação de profundo desequilíbrio, considerando que nesse jogo para que uns possam ganhar muito, outros terão de perder. A ES apresenta-se como uma possível alternativa ao modelo capitalista de empresa que 
teima em se posicionar como o único viável, "dentro da ideia de fim da história".

Ao analisar a estratégia nos empreendimentos de Economia Solidária de Londrina percebese que a grande maioria não possui planejamento formal, limitam-se a ações intuitivas e reativas diante do mercado. Em certos casos, parece haver um certo desprezo pela administração e tudo o que a envolve, preferindo-se discursos ideológicos onde a culpa é sempre do outro, seja o grande capital, o governo ou mercado. Muitas vezes parece se esquecerem que estão imersos numa economia de mercado e que a sobrevivência depende de um posicionamento adequado em relação a esta. Mas também não se pode relativizar a importância da ideologia e da visão política por detrás desses empreendimentos, ou facilmente se cai na lógica da empresa capitalista tradicional.

Luzio-dos-Santos e Borinelli (2010) próximos à visão de Barbosa (2007) entendem a necessidade de muitos empreendimentos de ES poderem contar com algum tipo de proteção ou privilégio por parte do poder público, considerando as características de boa parte dos seus membros, como a baixa escolaridade e formação técnica, histórico de miséria e subserviência, falta de conhecimentos e informações do mercado, escassez de recursos materiais, de know-how, capacidade de inovação, entre uma infinidade de outros obstáculos. Assim, os autores defendem uma mudança na letra da lei de compras públicas, capaz de privilegiar produtos e serviços provenientes de empreendimentos da Economia Solidária, o que já pode ser visto no caso aqui estudado da COOPERRREGIÃO.

Outra questão, que ficou evidenciada por meio do presente estudo, é a necessidade de aprimorar e, em alguns casos, criar ferramentais adequados à realidade da ES. A literatura na área ainda se concentra sobre questões ideológicas que, sem dúvida, são imprescindíveis, mas não se encontra o mesmo esforço em relação a conteúdos mais técnicos e adequados às necessidades e particularidades dos empreendimentos de ES e em linguagem apropriada ao público a que verdadeiramente se devem destinar.

Deste trabalho, fica evidente que a tensão entre questões e escolhas instrumentais (estratégicas) e substanciais da Economia solidária não é de fácil resolução. Mas, tratar do problema apenas no campo político e ideológico não é suficiente e parece constituir hoje um dos principais desafios teóricos e empíricos ao futuro da Economia Solidária. Duas tarefas complementares podem ser sugeridas para uma futura agenda de trabalho. Primeira: é preciso desnaturalizar, entre ativistas da Economia Solidária e pesquisadores tradicionais da estratégia, a ideia de que a estratégia é um recurso inerente à empresa capitalista; Segunda: é necessário reivindicar o espaço legítimo da produção de conhecimento e tecnologias sociais de gestão para a Economia Solidária na academia. Não obstante os seus limites e respeitadas as suas particularidades, a Economia Solidária continua 
representando uma alternativa econômica e de sociabilidade promissora, respondendo a diversas fragilidades e ameaças da economia tradicional.

Diante de um contexto reducionista e determinista que teima em entender a realidade de uma forma singular e não plural, em que se continua a procurar a única forma correta de gestão, novas possibilidades organizacionais veem surgindo em todo o mundo, algumas ainda muito tímidas outras já demonstram considerável vigor. O que se quer deixar claro é que necessitamos de alternativas, no plural, modelos organizacionais que consigam apontar para novas modalidades de empresas, que embora multifacetadas se aproximem na preocupação com a inclusão social, a democracia interna e a sustentabilidade.

\section{REFERÊNCIAS}

Ansoff, H. Igor e Mcdonnell Edward J. (1993) Implantando a administração estratégica. 2.ed (Trad.). Antônio Zorato Sanvicente. São Paulo: Atlas.

Bailey, A.; Avery, C. (1998) Discovering and defining the process of strategy development. In: Ambrosini, V.; Johnson, G.; Scholes, K. Exploring Techniques of Analysis and Evaluation in Strategic Management. London: Prentice Hall.

Barbosa, R.N.C. (2007) Economia solidária como política pública: uma tendência de geração de renda e ressignificação do trabalho no Brasil. São Paulo: Cortez.

BRASIL. (2009) Lei 11.947/2009 (Lei Ordinária). Publicada no D.O.U. de 17/06/2009. Dispõe sobre o atendimento da alimentação escolar e do programa dinheiro direto na escola aos alunos da educação básica, altera a Lei ${ }^{\circ}$ 10.880, de 9 de junho de 2004, 11.273, de 6 de fevereiro de 2006, 11.507, de 20 de julho de 2007; revoga dispositivos da Medida Provisória $\mathrm{n}^{\circ}$ 2.178-36, de 24 de agosto de 2001, e a Lei n 8.913, de 12 de julho de 1994; e dá outras providências. Brasília, 2009b. Disponível em <http://legislacao.planalto.gov.br/legisla/legislacao.nsf/viw_identificacao/lei\%20 $11.947-$ 2009?opendocument>. Acesso em: 22 de novembro de 2013.

Cattani, Antonio David (Org.). (2003) A outra economia. Porto Alegre: Veraz. 
Cruz, Zuleica G. e Luzio-Dos-Santos, Luis M. (2010) Economia solidária em Londrina: potencialidades e desafios. In. Borinelli, Benilson (Org.). A economia solidária em Londrina aspectos conceituais e a experiência institucional. Londrina.

Furtado, C. (1991) Formação Econômica do Brasil. Rio de Janeiro: Cia das Letras, 2009.

Ignácio, O. M. C.; Souza, L. M. S. (2010) Gestão estratégica aplicada ao cooperativismo solidário: uma alternativa de fortalecimento para os agricultores familiares. Disponível em:< http://www.sober.org.br/ palestra /9/885.pdf>. Acesso em: 20 de out. 2010.

Kotler, Philip. (2000) Administração de Marketing. 10ª ed. São Paulo: Prentice Hall.

Laro, Rodrigo. (2010) Marketing Social e Economia Solidária: uma aliança estratégica e inclusiva $\begin{array}{lllll}\text { para a } & \text { transformação } & \text { da } & \text { sociedade. } & \text { Disponível }\end{array}$ em:<http://www.socialtec.org.br/index.php?option=com>. Acesso em 21 de out. de 2010.

Luzio-Dos-Santos, Luis Miguel. (2010) Apostila de socioeconomia. Londrina. Universidade Estadual de Londrina.

Luzio-Dos-Santos, L.M.; Borinelli, B. (2010) Economia Solidária: propostas e perspectivas In: Borinelli, B.; Luzio-Dos-Santos, L.M.; Pitaguari, S.O.(Org.). Economia solidária em Londrina: aspectos conceituais e a experiência institucional. Londrina: Eduel.

Mance, E.A. (1999) A revolução das redes: a colaboração solidária como uma alternativa póscapitalista à globalização atual. Rio de Janeiro: Vozes.

Miles, R.; Snow, C. C. (1978) Organizational strategy, structure and process. London: Mc Graw Hill.

Mintzberg, H. (1994) The rise and fall of strategic planning. Hemel Hempstead: Prentice Hall.

Oliveira, Djalma P. R. (2005) Estratégia empresarial e vantagem competitiva. $4^{\text {a }}$ ed. São Paulo: Atlas.

Pochmann, Márcio. (2004) Políticas de Inclusão Social: resultados e avaliação. São Paulo: Cortez.

RodrigueS, Eduardo; Florbela Samagalo; Ferreira, Hélder; Mendes Maria M.; Januário, Susana. (2010) A pobreza e a exclusão social: teorias, conceitos e políticas públicas em Portugal. Disponível em: 〈http://ler.letras.up.pt/uploads/ficheiros/1468.pdf>. Acesso em: 06 de nov. 2010.

Sachs, I. (1996) Desenvolvimento, sustentável, sustentado. Rio de Janeiro: Garamond. 
Santos, B.S. (org.) (2002) Produzir para Viver: os caminhos da produção não capitalista. Rio de Janeiro: Civilização Brasileira.

Singer, Paul. (2002) A recente ressurreição da economia solidária no Brasil. In: Santos, Boaventura de Souza (Org.). Produzir para viver: Os Caminhos da Produção não Capitalista. São Paulo: Civilização.

. (2003) Economia solidária. In: Cattani, Antonio David (Org.). A outra economia. Porto Alegre: Veraz.

Treacy, Michael; WiersemA, Fred. (1995) A disciplina dos líderes de mercado: escolha seus clientes, direcione seu foco, domine seu mercado. 3. ed. Rio de Janeiro: Rocco.

Vasconcellos Filho, P. (1984) Planejamento estratégico para a retomada do desenvolvimento. Rio de Janeiro: Livros Técnicos e Científicos.

Vergara, Sylvia Constant. (2004) Projetos e relatórios de pesquisa em administração. 5.ed. São Paulo: Atlas.

Vieira, S. F. A.; Negreiros, L. F.; MelattI, G. ; Gimenez, F. A. P. ; Souza, J. F. C. F. ; Pelisson, C. (2013). Formação de estratégias em micro e pequenas empresas do comércio de londrina: uma abordagem sob a perspectiva das configurações. Revista da Micro e Pequena Empresa (FACCAMP), v. 7, p. 100.

\section{Recebido: 09/08/2013}

Aprovado: 07/10/2013 